\title{
MPRA
}

Munich Personal RePEc Archive

\section{Analytic hierarchy process and technique for order preference by similarity to ideal solution: a bibliometric analysis from past, present and future of AHP and TOPSIS}

MUKHERJEE, KRISHNENDU

HERITAGE INSTITUTE OF TECHNOLOGY

January 2014

Online at https://mpra.ub.uni-muenchen.de/59887/

MPRA Paper No. 59887, posted 26 Nov 2014 06:04 UTC 


\title{
Analytic hierarchy process and technique for order preference by similarity to ideal solution: a bibliometric analysis from past, present and future of AHP and TOPSIS
}

\author{
Krishnendu Mukherjee* \\ Department of Mechanical Engineering, \\ Heritage Institute of Technology, \\ Kolkata-700107, India \\ E-mail: gopal.mech2010@gmail.com \\ *Corresponding author
}

\begin{abstract}
Previous review papers on analytic hierarchy process (AHP) and TOPSIS (Technique for Order Preference by Similarity to Ideal Solution) mainly focused on the application areas and paid scant attention to the framework development of AHP, TOPSIS and their hybrid methods. The purpose of this paper is to review the literature on analytic hierarchy process (AHP), type of scale used in AHP, modified AHP, rank reversal problem of AHP, validation of AHP, application of AHP, TOPSIS, normalization methods for TOPSIS, distance functions for TOPSIS, fuzzy hierarchical TOPSIS, rank reversal problem of TOPSIS and various applications of TOPSIS to prepare a readymade reference for academician, research scholar and industry people. In this regard, research works are gathered from 1980 to 2013 (searched via ScienceDirect, IEEE etc) and out of which 61 research papers are critically assayed to depict the development of AHP, TOPSIS and their hybrid methods. Meaningful information and critical remarks are summarized in various tabular formats and charts to give readers easy information.
\end{abstract}

Keywords: AHP; TOPSIS; Fuzzy Hierarchical TOPSIS; Normalization methods; Rank reversal problem; Review.

Biographical notes: Krishnendu Mukherjee received his first class Bachelor of Engineering degree in Mechanical Engineering in 1998 from Jadavpur University and a Masters degree in Mechanical Engineering in 2002 from Birla Institute of Science and Technology, Pilani, India. He is pursuing his $\mathrm{PhD}$ from Jadavpur University, Kolkata, India. He has eleven years teaching experience in India and abroad. He also worked as a reviewer of EJOR, Elsevier and Journal of Operational Research Society, UK, PalGrave Macmillan publication,IJAHP,IJPE etc. Currently, 
he is an Assistant Professor with the Department of Mechanical Engineering, Heritage Institute of Technology, West Bengal, India. He has published papers in Computers and Industrial Engineering, International Journal of Applied Engineering Research, IEEE, International Journal of Business Intelligence and Systems Engineering, International Journal of Computational Systems Engineering etc. His main research areas include supplier selection, green supply chain, decision engineering, mass customisation and high frequency trading algorithm. His biography is also selected by Marquis Who's Who in 2014.

\section{Introduction}

"Decision making is the study of identifying and choosing alternatives based on the values and preferences of the decision maker. Making a decision implies that there are alternative choices to be considered, and in such a case we want not only to identify as many of these alternatives as possible but to choose the one that best fits with our goals, objectives, desires, values, and so on.." (Harris, 1980)

Decisions do not occur in isolation- the outcome of decision is always influenced by surrounding stimuli. Judicious judgment is the corner stone of everybody's success. Every human being takes decision which is a collection of cognitive processes involving perception, interpretation, imagination, reasoning and language (Saaty and Shih, 2009). Every rationale thinks to manipulate information which he/she received from surroundings to form concept, state reason, solve problem and make decision. Decision can be taken based on human intuition, past experience and on explicit and detailed reasoning. In general, decision making problem consists of following steps:

1. Define the problem: Purpose of this step is to identify root causes, constraints or limitation of the organization.

2. Determine requirements: Requirements are the constraints that describe the feasible solution space.

3. Establish goals: Goals are the objective that an organization is willing to achieve.

4. Identify alternatives: Alternatives are the means to achieve goal. All alternatives must meet requirements.

5. Define criteria: Goals are represented in form criteria. Every goal must have at least one criterion. Criteria are used to measure suitability of alternatives to achieve goal.

6. Select a decision making tool: There are several tools for decision making problem. Selection of problem depends upon type of problem and objective of the decision maker. 
7. Evaluate alternatives against criteria: Alternatives are assessed by objective judgment or subjective judgment or combination of two to measure its suitability with respect of a criterion to achieve desired goal. Finally, alternatives are ranked as per the preference of decision makers.

8. Validate solutions against problem statement: Selected alternatives should be judged with respect to requirements and goal of the problem.

In 1980, Saaty proposed analytic hierarchy process, a graphical representation of problem to understand and solve problem easily. The term "problem" refers the dissatisfaction perceived from some ongoing situation. People take action to get rid of such situation and they make decision to take action. Usually, solving complex problem needs cognition, pattern matching, associative memory and knowledge, judgment, comparisons, and imagination of human brain. Multi-criteria decision analysis (MCDA) is an essential approach to solve complex real life problem. The family of MCDA is broadly classified as multi-attribute decision making (MADM) and multi-objective decision making (MODM). MADM is applicable for finite set of alternatives and MODM is applicable for infinite number of alternatives. The MCDA methodology can be considered as a non-linear recursive process consists of four steps: (i) structuring the decision problem, (ii) articulating and modeling the preferences, (iii) aggregating the alternative evaluations (preferences) and (iv) making recommendations (Guitouni and Martel, 1998). Opricovic and Tzeng (2004) define the main steps of MCDM as follows:

1. Establishing system evaluation criteria relating system capabilities to goals.

2. Develop alternatives systems for achieving goals.

3. Assessing alternatives in terms of criteria.

4. Employing a standard multi-criteria analysis tool or techniques.

5. Accepting one alternative as optimal choice from the outcome of multi-criteria analysis.

6. Aggregating new information and going into nest iteration of multi-criteria optimization if the final solution is not accepted.

Decision can be broadly classified as rational decision, irrational decision and non-rational decision. In a rational decision, alternatives are evaluated first and then choosing the one that maximizes the DM's satisfaction or his 
utility function. The decision based on the DM's experiences and knowledge is qualified as a non-rational decision. The irrational decision considers only the personal aspirations and aversions (Guitouni and Martel, 1998). MCDA methods are used to prepare DMs preference model which based on performance aggregation oriented and performance aggregation based. MCDA is applicable for finite number of alternatives and it can be classified as follows:

1. The single synthesizing criterion approach without incomparability (TOPSIS,AHP etc)

2. The outranking synthesizing approach (ELECTRE, ORESTE etc)

3. The interactive local judgments with trial-and-error approach.

Table 1.1 here

Majority of the review papers on MCDA tools gathers scholarly papers to categorize them into application areas, publication year, journal name, authors' nationality etc and give less importance to paper related to framework development of MCDA tools. On the other hand, thorough understanding MCDA framework is highly important to take good decision. Considering this need a state-of the-art literature survey on TOPSIS (Technique for Order Preference by Similarity to Ideal Solution) and analytic hierarchy process (AHP) is conducted in this paper and a repository has been established based on framework development of AHP and TOPSIS, which includes 61 papers published in various scholarly journals since 1980. Contributions of this paper are threefold: developing a clear understanding about decision, type of decision, AHP and TOPSIS, a structured review on framework development that provides a guide to earlier research on the AHP and TOPSIS method, and identifying research issues for future investigation.

The rest of the paper is organized as follows. Section 2 gives detail discussion about analytic hierarchy process, section 3 discusses about different type of scale - a must for effective use of MCDA tools, section 4 depicts about selection of prioritization methods, section 5 discusses about the rank reversal problem in AHP with solution, section 6 gives details about validation of AHP, section 7 gives a brief introduction to modified AHP, section 8 discusses about application of AHP, section 9 gives an introduction to TOPSIS, comparison of AHP and TOPSIS and different normalization methods for TOPSIS, section 10 discusses about fuzzy 
hierarchical TOPSIS, section 11 discusses about rank reversal problem in TOPSIS with solution, section 12 and 13 discusses about different methods and application of TOPSIS and section 14 concludes with critical remarks and future research work of AHP and TOPSIS.

\section{Analytic hierarchy process (AHP)}

"It (AHP) combines both subjective and objective assessments into an integrative framework based on ratio scales from simple pair wise comparisons. The technique requires three steps: structuring the hierarchy, pair wise comparisons to yield priorities, and synthesis of the priorities into composite measure of the decision alternatives or options. " (Schoner and Wedley, 1989 as mentioned in Malcom Beynon, 2002)

Following steps are used for analytic hierarchy process:

Step 1: Determine goal.

Step 2: Identifying the criteria and sub criteria for goal.

Step 3: All sub-criteria are broadly categorized as operational dimension and strategic dimension.

Step 4: Prepare pair-wise comparison matrix with saaty's nine point preference scale. Let $\mathrm{A}$ is a $\mathrm{n} \mathrm{x} \mathrm{n}$ pair-wise comparison matrix.

$\mathrm{A}=\left[\begin{array}{lll}a_{11} & a_{21} \ldots . & a_{1 n} \\ a_{21} & a_{22} \ldots . & a_{2 n} \\ a_{n 1} & a_{n 2} \ldots . & a_{n n}\end{array}\right] \quad$ Here, diagonal elements are all equal to 1.

Step 5: Normalize the matrix with geometric mean as follows

$w_{i}=\frac{\left[\sum_{j=1}^{n} a_{i j}\right]^{1 / n}}{\sum_{i=1}^{n}\left[\sum_{j=1}^{n} a_{i j}\right]^{1 / n}} \quad \mathrm{i}, \mathrm{j}=1,2,3 \ldots \ldots . . \mathrm{n}$

Step 6: Perform consistency check. If $\mathrm{C}$ denotes $\mathrm{n}$ dimensional column vector describing the sum of $\mathrm{C}=\left[C_{i}\right]_{\mathrm{nx} 1}=\mathrm{AW}^{\mathrm{T}}, \mathrm{i}=1,2, \ldots \ldots \mathrm{n}$

Where $\mathrm{AW}^{\mathrm{T}}=\left[\begin{array}{cccc}1 & a_{12} \ldots \ldots & a_{1 n} \\ a_{21} & 1 \ldots \ldots & a_{2 n} \\ a_{n 1} & a_{n 2} \ldots \ldots & 1\end{array}\right]\left[w_{1} w_{2} \ldots \ldots w_{n}\right]=\left[\begin{array}{c}C_{1} \\ C_{2} \\ C_{n}\end{array}\right]$

Step 7: To avoid inconsistency in judgment, saaty proposed the use of maximum eigen value $\lambda_{\max }$ to calculate effectiveness of judgment. The maximum eigen value $\lambda_{\max }$ can be determined as follows:

$\lambda_{\max }=\frac{\sum_{i=1}^{n} c v_{i}}{n}, \quad \mathrm{i}=1,2,3 \ldots \ldots \ldots . \mathrm{n}$

Step 8: Estimate consistency index (CI) with $\lambda_{\max }$ value as follows:

$\mathrm{CI}=\frac{\lambda_{\max -n}}{n-1}$

Step 9: Determine consistency ratio (CR) to check consistency 
$\mathrm{CR}=\frac{C I}{R I}$, where $\mathrm{RI}$ denotes average random index. In this regard, different RI values are shown in table 1.2. For consistency, CR value should be less than equal to 0.1 .

Table 1.2 here

Other forms of $\mathrm{CI}$ also exist but lack in capability to remove contradictory judgments. Geometric Consistency Index (GCI) calculates the sum of the difference between the ratio of calculated priorities (Crawford and Williams, 1985; Aguarón \& Moreno-Jiménez, 2003). Alonso and Lamata (2006) prepared random index with their regression model. Irrespective of several forms of CI, Saaty's CI is used most extensively because of its capability to measure inconsistency of judgment.

\section{Type of Scale}

There are two types of judgment-comparative judgment and absolute judgment. In comparative judgment, some relation between two observed entities is derived. In absolute judgment, observer rates the single entity by some previously experienced measurement scale. To compare several criteria, sub-criteria and alternatives, observer or decision maker has to deal with several scales. Hence, synthesizes of scales and validity of the process of comparison is essential to make comparison in most scientific way. A scale is a triplet, consists of a set of numbers, a set of objects and mapping of objects to the number (Saaty, 2004). There are different types of scale such as

1. Nominal scale: A number is assigned to each object. For example, usually in every bank token number is assigned to each customer who is in queue to withdraw cash.

2. Ordinal scale: Numbers are assigned to each object to represents their order, increasing or decreasing.

3. Interval scale: It invariant under a positive linear transformation. For example, converting Celsius to a Farenheit temperature reading (Saaty,2004)

4. Ratio scale: It is a similarity transformation where a nondimensional parameter is used to convert one form of unit to other. For example, $\mathrm{y}=\mathrm{Bx}$ where $\mathrm{B}>0$ 
5. Absolute scale: Number is used directly for pair wise comparison. It is basically identity transformation. For example, number used in counting students in class room.

Apart from above, there are eight different scales as mentioned by Ishizaka and Labib (2011), shown in table 1.3.

\author{
Table 1.3 here
}

As shown in table 3, if $\mathrm{c}=1$ then $\mathrm{A}=\mathrm{B}$; if $\mathrm{c}>1$ then $\mathrm{A}>\mathrm{B}$ and for $\mathrm{A}<\mathrm{B}$ reciprocal values of $1 / \mathrm{c}$ is used. Commonly,Saaty scale and Geometric scale is used. However, Saaty scale is not transitive type whereas Geometric scale is considered as transitive scale (Dong et al., 2008). On the other hand, Saaty (1994) mentioned that determination of parameter of Geometric Scale is difficult. Hence, selection of appropriate scale is essential for each problem. It is pertinent to mention that work of Ishizaka and Labib (2011) is limited to methodological development of AHP and didn't discuss about various modified methods of AHP to tackle rank reversal problem which is mentioned in sec. 5 of this paper.

\title{
4 Prioritization Methods - EM or LLSM which one is better
}

Process of deriving priorities from pair wise comparison matrix is known as prioritization. There are several prioritization methods (Srdjevic, 2005; Choo and Wedley, 2004) and among all most common prioritization methods are

\section{Eigen value method (EM)}

2. Logarithmic Least Square Method (LLSM)

Selection of best prioritization method is an open research issue. In this regard, Dong et al. (2008) proposed two algorithms to measure the performance of four scale and prioritization methods. According to Saaty (1990) ten best reasons for using eigen value method are as follows:

“(1) Uniqueness of solution.

(2) Simplicity is not a good criterion, there are simple methods that are extremely unattractive.

(3) Rank reversal with different methods; they cannot all be legitimate.

(4) Dominance rather than minimization of errors. 
(5) EM procedure is descriptive; all others are technically prescriptive and involve minimization.

(6) Direct analytical, not statistical, relation between the solution and consistency measurement that does not depend on assuming distributions.

(7) Statistical indices of bias are not applicable to the eigenvector which is concerned with order preservation.

(8) Basic approach generalizes systems with feedback.

(9) Successive weighting of criteria according to importance leads to the eigenvector.

(10) Left and right eigenvector connection to consistency; this is not an issue with other methods."

\section{Problem of Rank Reversal in AHP - How to Tackle?}

Rank reversal phenomenon can be defined as the change of the relative rankings of alternatives due to addition or deletion of an alternative. In 1982, Belton and Gear raised issues of rank reversal for analytic hierarchy process and mentioned a new normalization method to overcome shortcoming of Saaty's AHP. In reply, Saaty and Vargas (1984) proposed that rank reversal does occur in AHP due to addition of new alternatives and it is acceptable. In the same paper, they depicted with example that rank reversal does occur for the normalization method proposed by Belton and Gear (1984) and also mentioned the following observations due to addition of new alternatives:

1. Addition of new alternative cannot change rank order if the new alternative is strongly dominated by least preferred alternative for every criterion.

2. Similarly, addition of new alternative cannot change rank order if the new alternative dominates the most preferred alternative for every criterion.

3. If the new alternative falls between two specific alternatives for every criterion then its final rank will fall between these two alternatives, but rank may be reversed elsewhere.

Wang and Elhag (2006) identified the following causes of rank reversal:

1. In MCDA, priorities are considered as utilities. Any change in utilities may change the final ranking of alternatives. 
2. In MCDA, the weights of criteria are usually assumed to be independent of number of alternatives. If the weights or number of criteria are changed then there is no need to preserve rank. In such situation rank reversal is accepted.

3. To preserve rank of each alternative after addition of new alternative, original local priorities of every alternative under every criterion should remain unchanged.

4. Let $\mathrm{A}=\left(a_{i j}\right)_{n x n}$ is the comparison matrix with respect to some criterion. After the addition of new alternative comparison matrix becomes $\mathrm{A}^{1}=\left(a_{i j}\right)_{(n+1) x(n+1)}$. There eigenvector weights are represented by $W_{A}=\left[W_{1 A}, W_{2 A}, \ldots \ldots \ldots, W_{n A}\right]^{T}$ and $W_{A^{1}}=$ $\left[W_{1 A}, W_{2 A}, \ldots \ldots ., W_{(n+1) A}\right]^{T}$. The necessary condition to preserve rank of alternatives after addition of new alternative is to

$$
\sum_{i=1}^{n} W_{i A}=\sum_{i=1}^{n+1} W_{i A^{1}}=1
$$

To overcome the rank reversal problem of MCDA following modified methods of AHP are developed

1. B-G modified AHP, proposed by Belton and Gear (1985).

2. Referenced AHP, proposed by Schoner and Wedley (1989).

3. Linking pin AHP, proposed by Schoner et al. (1997).

4. Multiplicative AHP, proposed by Barzilai and Lootsma (1997).

\section{Validation of AHP}

Any scientific truth relies on two important parameters - the guiding principle and the process of empirical verification. Validity of decision making process depends on choice of numerical scale and method of prioritization (Dong et al., 2008). There are two kinds of decisions- one is what we prefer the most, known as normative decision making and other is how to make the best choice considering all the influences around us that can affect optimality of any choice we make (Whitaker,2007). Like other scientific theory, decision makers should prepare the model which is the replica of real life problem or the model contains all characteristics of real life problem. Such simplification of real life problem may create several limitations of the proposed model. Therefore validation of the 
model is very important issue in decision science. In this regard, interested reader can refer work of Whitaker (2007) which contains ample examples on validation. According Qureshi et al. (1999) evaluation of any model consists of following three steps:

1. Verification: It means to build the model correctly. If it in a form of computer program to calculate any variable then obtained result should be at par the desired result.

2. Validation: It determines appropriateness of the proposed model. It encompasses data validity, conceptual validity and operational validity.

3. Sensitivity: If the parameters are changed individually or in combination then what would be the expected outcome is tested by sensitivity analysis.

Statistical inference approaches (such as hypothesis test and confidence intervals) and descriptive statistics (such as means, variances, autocorrelation coefficients and graphs) are commonly used to compare any proposed model with real life problem (Qureshi et al.,1999). As mentioned by Qureshi et al. (1999), stated in table 1, following methods are identified for validation of MCDA methods and they are mentioned as follows:

1. Sensitivity analysis by changing criteria scores.

2. Develop credibility of model by asking questions to relevant users/group representative.

3. Validation of the proposed model by taking comments from users.

4. Sensitivity of result regarding uncertainty of weight and scores.

5. Validation and verification is used along with sensitivity analysis.

Result obtained from proposed model may differ from the result obtained in real life because the proposed model is either incorrect or not in position to handle uncertainty properly. Classical AHP considers crisp values for pair wise comparison. Instead of AHP fuzzy AHP is commonly used to deal uncertainties. However, Saaty and many other researchers showed that use of fuzzy set with AHP brings more fuzziness to the problem and spoil final result. Hence, it is justified to discard the use of fuzzy AHP. On the other hand, Rosenbloom (1996) proposed probabilistic interpretation of final rankings in AHP. Aguarón et al. (2003) proposed consistency stability interval (CSI), an interval range associated with every judgment of pair wise comparison. To calculate CSI a row geometric 
mean method is discussed in their work. In this regard, author categorizes causes for validation of model into two categories:

1. Internal Cause: A model may need verification and validation for the following internal causes

1. Misinterpretation of real life problem.

2. Selection of wrong MCDA tools.

3. Fails to identify the uncertainty associated with judgment.

4. Selection of wrong scale and norm for aggregation of judgment.

2. External Cause: A model may need verification and validation for the following external causes

1. Collection of wrong or misleading data.

2. Fails to identify external uncertainty associated with the outcome of the model. For instance, demand of a product is a function of price. Any uncertainty in price will change the demand of a product and thereby, discrepancies may develop between the obtained result and actual result.

Some of the internal causes and external causes are uncontrollable in nature and they may change outcome of any proposed model. Therefore it is up to the decision makers how to tackle such uncontrollable causes in their proposed model with their years of experience and expertise.

\section{Modified AHP}

Literature review shows strong inclination to use AHP in different areas such as manufacturing, design, thermal, supply chain management, logistics etc. Recent trend shows use of hybrid AHP instead the use of classical AHP. For instance, AHP is integrated with Principal Component Analysis to conduct subjective and objective analysis of real life problem. In this regard, a partial list of modified AHP is shown in table1.4.

Table 1.4 here 


\section{Application of AHP}

From early 70s, AHP has become one of the pervasive MCDA tool and got immense appreciation in different areas of research because of its computational simplicity, flexibility to be integrated with other techniques irrespective of its limitations. Mukherjee et al. (2013) mentioned in their paper that AHP is one of the most preferred methods for supplier selection. In this regard, three review works are identified since 1979 onwards, shown in table 1.5, to explore various applications of AHP.

Table 1.5 here

\section{Technique for Order Preference by Similarity to Ideal Solution (TOPSIS)}

TOPSIS is a multiple criteria method to identify solutions from a finite set of alternatives based upon simultaneous minimization of distance from an ideal point and maximization of distance from a nadir point (Olson, 2004). It is one of the classical MCDM approach, based on aggregating function to find a solution which is nearest to positive ideal solution and farthest from negative ideal solution, however it does not consider relative importance of these distances (Opricovic and Tzeng, 2004). In 1981, Hwang and Yoon developed a new technique; popularly known as TOPSIS, based on improved version of Zeleny (1974). The process of TOPSIS includes following six successive steps (Hwang and Yoon, 1981):

1. Construction of normalized decision matrix.

2. Construction of weighted normalized decision matrix.

3. Determination of positive ideal solution and negative ideal solution.

4. Calculation of the separation measure.

5. Calculation of relative closeness to positive ideal solution.

6. Ranking of the alternative.

Like other MCDA tools, attributes as well as alternatives should be fixed before the onset of TOPSIS. Hence, different group decision making methods (GDMs) such as brain storming, nominal group technique (NGT), Delphi technique etc can be used to carefully acquire prerequisite of MCDA tools to ensure quality of decision (Shih et al., 2001). A relative advantage of TOPSIS is the ability to identify the best alternative quickly (Parkan and Wu, 1997). Like other MCDA tools, method of normalization 
for TOPSIS can be simplified as linear transformation (Saghafian and Hejazi, 2005; Chen, 2000). Considering the simplicity of TOPSIS, many researchers proposed different methods to use TOPSIS in fuzzy environment. Broadly, in two different ways classical TOPSIS can be used for fuzzy environment -

\section{Defuzzification of ratings and weights into crisp value. \\ 2. Generalized TOPSIS in fuzzy environment.}

Usually, second method is better than first as it preserves the loss of information during defuzzification. Wang and Lee (2007) proposed a generalized TOPSIS in fuzzy environment with two parameters, Up and Lo. If decision makers cannot reach an agreement or consensus on by using linguistic variables based fuzzy sets, then interval-valued fuzzy set theory can provide a more accurate modelling. In this regard, extension of fuzzy TOPSIS method is proposed by Ashtiani et al. (2009) based on interval-valued fuzzy sets. Chu and Lin (2009) proposed novel algorithm of TOPSIS to represent membership function of each fuzzy weighted rating by interval arithmetic of fuzzy numbers. Wang and Lee (2009) proposed new method for TOPSIS to consider both subjective and objective weight to evaluate alternative with respect to attributes. Their proposed weighting mechanism can avoid the subjectivity from the DM's personal bias and confirm the objectivity. Nezhad and Damghani (2009) presented TOPSIS approach based on preference ratio to rank alternatives based on closeness co-efficient. Chen and Tsao (2008) presented a comparative analysis of interval-valued fuzzy TOPSIS rankings from and discussed in detail on consistency rates, contradiction rates, and average Spearman correlation co-efficient. They recommended that consistency rate between two distance measures gradually reduces as the number of alternatives increases in the problem. Shih et al. (2007) proposed an extension of TOPSIS with internal aggregation. Taleizadeh et al. (2009) proposed integrated method of Pareto, TOPSIS and GA to solve random fuzzy replenishment of inventory. In their work, they recommended to use other meta-heuristic algorithm with TOPSIS such as Particle Swarm Optimization (PSO), Simulated Annealing (SA), Ant-Colony Optimization Tabu-Search etc to solve integer non-linear optimization problem. Tsou (2008) integrated multi-objective particle swarm optimization (MOPSO) with TOPSIS to solve inventory issues. Lin et al. (2008) presented a frame work to integrate AHP and TOPSIS to identify customer requirements and design characteristics to develop better product for customer. 
Table 1.6 here

Table 1.7 here

Table 1.8 here

\section{Fuzzy Hierarchical TOPSIS}

Proposed method of Chen (2000) has following weaknesses:

1. The need to assign an initial weight to each criterion.

2. When fuzzy numbers $\sim 1, \sim 0$ are directly assumed to be the fuzzy PIS and NIS, respectively, and when the weighted and graded values are extremely small, then the distance between criterion and the fuzzy PIS and NIS is increased. The result will lie outside the range $[0,1]$.

3. The result sometimes does not conform to the basic conception that the best solution should be that nearest PIS and farthest from NIS.

To overcome such limitations, Wang et al. (2008) proposed fuzzy hierarchical TOPSIS which has four main components:

1. FAHP uses a hierarchical structure to calculate the fuzzy weight of each criterion.

2. TOPSIS uses the criterion characteristics to establish a normalized fuzzy performance matrix and then multiplies all the criterion weights to form a normalized weight performance matrix.

3. Obtain FPIS and FNIS, and apply the metric distance method to calculate the dispersion between the alternative value under each criterion, and under FPIS and FNIS.

4. Finally, apply Euclidean distance to aggregative the dispersions to judge and get a best ranking.

The algorithm of fuzzy hierarchical TOPSIS is as follows:

Step 1: Confirm the evaluation criteria and alternatives of the decisionmaking problem, and establish a hierarchical structure.

Step 2: Use pair-wise comparison to get the degree of importance of all criteria, and evaluate all of the alternatives under each criterion, then ask 
experts to assign the alternatives an appropriate fuzzy number based on the linguistic variable to form a fuzzy judgment matrix.

Step 3: Use the Lambda-Max method to calculate the fuzzy weight (FAHP) of each criterion given by the experts.

Step 4: Check the consistency index (C.I.)

Step 5: Through the geometry average method, integrate all the expert opinions to obtain fuzzy weight for every aggregative criterion.

Step 6: Establish a normalized fuzzy performance matrix.

Step 7: Get the weighted normalized fuzzy performance matrix.

Step 8: Determine FPIS and FNIS.

Step 9: Calculate the distance between each point and FPIS and FNIS by the metric distance method.

Step 10: Apply the Euclidean distance method to aggregate all of the criteria for each alternative.

Step 11: Select the best alternative.

\section{Rank reversal problem in TOPSIS}

Rank reversal is a phenomenon when previous rank of alternatives is altered due to addition/deletion of any alternative. If two alternatives have same preference under all criteria then their corresponding rank depends on evaluation approach of TOPSIS.

Cascales and Lamata (2012) mentioned two main causes of rank reversal problem in TOPSIS are as follows:

\section{Norm used in TOPSIS approach.}

2. Selection of positive ideal solution and negative ideal solution.

In classical TOPSIS, vector normalization is used. It can be represented as

$$
r_{i j}=\frac{x_{i j}}{\sum_{j=1}^{m}\left(x_{i j}\right)^{2}} \forall i=1,2,3, \ldots \ldots, m \text { and } j=1,2,3, \ldots, n
$$

Chakraborty and Yeh (2009) mentioned that vector normalization is most appropriate to maintain consistency in ranking and is able to handle weight sensitivity quite well. However, Cascales and Lamata (2012) proposed that $r_{i j}=\frac{x_{i j}}{\max _{i}\left(x_{i j}\right)} \forall i=1,2, \ldots$, m where $r_{i j} \leq 1 \quad$ is appropriate for preserving rank. They further mentioned that along with modification of norm, modification of selection method for positive ideal and negative ideal solution is required. For instance, after addition of new 
alternative if the normalize matrix $A=\left[r_{i j}\right]_{m x n}$ where $\max \left(r_{i j}\right)=$ $1 \forall i=1,2, \ldots, m$ and $j=1,2, \ldots, n$ then positive ideal solution (PIS) becomes $A^{+}=[1,1, \ldots, 1]$.Here, PIS remains unchanged. However, there are chances that negative ideal solution (NIS) $A^{-}=\left[\min \left(r_{i j}\right)\right]$ may change and thereby change the closeness co-efficient as well ranking of alternatives.

\section{TOPSIS and Other Methods}

"The recent trend of TOPSIS papers has shifted towards applying the combined TOPSIS rather than the stand-alone TOPSIS. These combinations have made the classical TOPSIS method more representative and workable when handling practical and theoretical problems." (Behzadian et al., 2012)

TOPSIS is one of the most popular MCDA tool for its computational simplicity and other advantages of TOPSIS are mentioned as follows (Govindan et al., 2012):

1. An unlimited range of criteria and performance attributes can be included.

2. It allows explicit trade-offs and interactions among attributes. More precisely, changes in one attribute can be compensated for in a direct or opposite manner by other attributes.

3. Preferential ranking of alternatives with a numerical value that provides a better understanding of differences and similarities between alternatives, whereas other MADM techniques (such as the ELECTRE) methods only determine the rank of each alternative.

4. Pair wise comparisons, required by methods such as the AHP, are avoided. This method is especially useful when dealing with a large number of alternatives and criteria.

5. It is a relatively simple computation process with a systematic procedure.

6. According to the simulation comparison from Zanakis et al. (1998), TOPSIS has the fewest rank reversals when an alternative is added or removed among the MADM methods. 


\section{Application of TOPSIS}

Behzadian et al. (2012) identified nine areas of application of TOPSIS and its integrated approach - Supply Chain Management and Logistics; Design, Engineering and Manufacturing Systems; Business and Marketing Management; Health, Safety and Environment Management; Human Resources Management; Energy Management; Chemical Engineering; Water Resources Management and other topics. Based on work of Behzadian et al. (2012) fig. 1 is prepared.

Fig 1 here

\section{Conclusion and future research work}

Better decision means better understanding of problem and better understanding of MCDA tools to select best alternative/s. Better understanding of MCDA tools means clear understanding of algorithm and proper selection of scale,selection of normalization method,selection of random indices,process of validation etc.Purpose of this review paper is to give better understanding of MCDA framework in light of two most cited MCDA tools - AHP and TOPSIS. Both AHP and TOPSIS are most cited MCDA tool because of simplicity of calculation and easy understaing.

Selection of appropriate scale, synthesizes of scales, validity of the process of comparison and selection of best prioritization is essential to make comparison in most scientific way. Finally, this paper shows that verification, validation and sensitivity analysis (VVS) is an essential characteristic of any good decision making process.

Some theoretical disputes do exist for AHP and TOPSIS. Rank reversal problem is one of them.But it can be resolved with simple modification of algorithm as per the requirement of the problem. However, thorough understanding of causes of rank reversal problem and method of preserving rank is a priori for decision making process. Computational complexity could be another problem as it degrades efficiency of algorithm by increasing computational time for large problem.

Real life problem encompasses verious uncertainties. Commonly fuzzy set theory (FST) is used with classical MCDA tools to deal with imprecision 
or vagueness of decision making process. In this regard, author strongly suggest to avoid direct defuzzification of fuzzy members during pair wise comparison to avoid loss of data. Recent trend of research shows that researchers are keen to integrate to different MCDA tools to get advantages of both. Still more researck work is required in the following areas:

1. Development of appropriate hybrid method of AHP/TOPSIS to deal with large no of criteria and alternatives for complex real world problem.

2. In TOPSIS, best solution is identified by measuring its distance from positive ideal solution and negative ideal solution. Hence, more research work is required to explore the significance of such distance measure.

3. Selection of appropriate scale and prioritization method to study validation of decision making process.

\section{Acknowledgements}

Author expresses gratitude to two anonymous reviewers for their valuable comments and detailed reading of the paper.

\section{References}

Akhlaghi, E.(2011) 'A Rough-set Based Approach to Design an Expert System for Personnel Selection', World Academy of Science, Engineering and Technology,Vol.78, pp.245-248.

Ashtiani, B., Haghighirad, F. , Makui, A. and Montazer, G. A. (2009) 'Extension of fuzzy TOPSIS method based on interval-valued fuzzy sets', Applied Soft Computing, Vol. 9, pp. 457-461.

A.AZadeh and Izadbaksh,H.R.(2008) 'A Multi-Variate /Multi-Attribute Approach For Plant Layout Design’, International Journal of Industrial Engineering, Vol.15,No.2, pp.143-154.

Alonso, J., and Lamata, T. (2006) 'Consistency in the Analytic Hierarchy Process: a New Approach', International Journal of Uncertainty, Fuzziness and Knowledge-Based Systems, Vol.14, pp.445-459.

Aguarón, J., Esocbar,M.T. and Jiménez, J.M.M. (2003) 'Consistency stability intervals for a judgement in AHP decision support systems', European Journal of Operational Research, Vol 145,pp.382-393.

Aguarón, J., and Moreno-Jiménez, J. (2003) 'The geometric consistency index: approximated thresholds', European Journal of Operational Research, Vol.147, pp.137-145.

Behzadian , M., Otaghsara, S. K., Yazdani, M. and Ignatius, J. (2012) 'A state-of the-art survey of TOPSIS applications’, Expert Systems with Applications, Vol.39, pp.13051-13069. 


\section{Past, present and future of AHP and TOPSIS}

Beynon, M. (2002) 'An analysis of distributions of priority values from alternative comparison scales within AHP’, European Journal of Operational Research, Vol. 140, pp. 104-117.

Barzilai, J., Lootsma, F.A. (1997) 'Power relations and group aggregation in the multiplicative AHP and SMART ‘, Journal of Multi-Criteria Decision Analysis, Vol. 6,pp. 155-165.

Belton, V. and Gear, T. (1982) 'On a shortcoming of Saaty's method of analytic hierarchies', Omega, Vol.11, No.3, pp. 226-230.

Belton, V. and Gear,T. (1985) 'The legitimacy of rank reversal - a comment', Omega ,Vol.13 ,pp. 143-144.

Cascales, M. S. G. and Lamata, M. T. 2012 'On rank reversal and TOPSIS method', Mathematical and Computer Modelling, Vol. 56, pp. 123-132.

Chu, T.C. and Lin, Y.C.(2009) 'An interval arithmetic based fuzzy TOPSIS model', Expert Systems with Applications, Vol. 36, pp. 10870-10876.

Chakraborty, S. and Yeh, C.H. (2009) 'A Simulation Comparison of Normalization Procedures for TOPSIS’, IEEE, ISSN: 978-1-4244-4136-5/09.

Chen, T.Y. and Tsao, C.Y. (2008) 'The interval-valued fuzzy TOPSIS method and experimental analysis', Fuzzy Sets and Systems, Vol.159 ,pp. $1410-1428$.

Choo, E.U. and Wedley, W.C.(2004) 'A common framework for deriving preference values from pair wise comparison matrices', Computers \& Operations Research, Vol. 31,pp.893-908.

Chen, C.T.(2000) 'Extensions of the TOPSIS for group decision making under fuzzy environment', Fuzzy Sets and Systems, Vol. 114, pp. 1-9.

Crawford, G., and Williams, C. (1985) 'A note on the analysis of subjective judgement Matrices', Journal of Mathematical Psychology, Vol.29, pp.387-405.

David P. Lilly,John Cory and Bill Hissem (2009) 'The Use Of Principal Component Analysis To Integrate Blasting Into The Mining Process', Proceedings of 2009 Oxford Business \& Economics Conference Program, St. Hugh's College, Oxford University, Oxford, UK, June 24-26.

Dong, Y., Xu, Y., Li, H. and Dai, M. (2008) 'A comparative study of the numerical scales and the prioritization methods in AHP', European Journal of Operational Research, Vol. 186 , pp. 229242 .

Govindan, K., Khodaverdi, R. and Jafarian, A. (2012) 'A fuzzy multi criteria approach for measuring sustainability performance of a supplier based on triple bottom line approach', Journal of Cleaner Production, pp. 1-10, doi:10.1016/j.jclepro.2012.04.014.

Guo, Z. and Zhang, Y.(2010) 'The third-party logistics performance evaluation based on the AHPPCA model', IEEE, ISSN-978-1-4244-7161-4/10.

Guo,C.G.,Liu,Y.X.,Hou, S.M. and Wang,W.(2010) 'Innovative Product Design Based on Customer Requirement Weight Calculation Model',International Journal of Automation and Computing, Vol.7, No.4,pp.578-583.

Guitouni, A. and Martel, J.M. (1998) 'Tentative guidelines to help choosing an appropriate MCDA method', European Journal of Operational Research, Vol. 109 ,pp. 501-521. 


\section{Krishnendu Mukherjee}

Hwang, C.L.and Yoon, K.(1981) Multiple Attribute Decision Making. In: Lecture Notes in Economics and Mathematical Systems 186, Springer-Verlag, Berlin.

Ishizaka, A. and Labib, A. (2011) 'Review of the main developments in the analytic hierarchy process, Expert Systems with Applications, Vol. 38,pp. 14336-14345.

Jacques, T. J., Delhaye, C. And Kunsch, P. L. (1989) 'An Interactive Decision Support System (IDSS) For Multicriteria Decision Aid', Mathematical Computer Modeling, Vol. 12, No. 10/11, pp. 1311-1320.

Lin, M.C., Wang, C.C., Chen, M.S. and Chang, C. A. (2008) 'Using AHP and TOPSIS approaches in customer-driven product design process', Computers in Industry, Vol. 59, pp. 17-31.

Li, T.-S. and Huang, H.-H.(2009) 'Applying TRIZ and Fuzzy AHP to develop innovative design for automated manufacturing systems', Expert Systems with Applications, Vol.36, pp.8302-8312.

Mukherjee, K., Sarkar,B. And Bhattacharyya,A. (2013) 'Supplier selection by F-compromise method: a case study of cement industry of NE India', International Journal of Computational Systems Engineering, Vol.1, No. 3, pp. 162-174.

Nezhad, S. S. and Damghani, K. K. (2009) 'Application of a fuzzy TOPSIS method base on modified preference ratio and fuzzy distance measurement in assessment of traffic police centers performance', Applied Soft Computing, doi:10.1016/j.asoc.2009.08.036.

Najmia,A.and Makuia, A.(2010) 'Providing hierarchical approach for measuring supply chain performance using AHP and DEMATEL methodologies', International Journal of Industrial Engineering Computations, Vol.1,pp.199-212.

Opricovic, S. and Tzeng, G.H.(2004) 'Compromise solution by MCDM methods: A comparative analysis of VIKOR and TOPSIS', European Journal of Operational Research, Vol. 156,pp. 445455 .

Olson, D.L. (2004) 'Comparison of Weights in TOPSIS Models', Mathematical and Computer Modelling, Vol.40, pp.721-727.

Parkan, C. and Wu, M.L. (1997) 'On the equivalence of operational performance measurement and multiple attribute decision making', International Journal of Production Research, Vol. 35, No.11, pp. 2963-2988.

Qureshi, M.E., Harrison, S.R. and Wegener, M.K. (1999) 'Validation of multicriteria analysis models', Agricultural Systems, Vol. 62 , pp. 105-116.

Rosenbloom, E.S.(1996) 'A probabilistic interpretation of the final rankings in AHP', European Journal of Operational Research,Vol.96, pp. 371-378.

Subramanian, N. and Ramanathan, R. (2012) 'A review of applications of Analytic Hierarchy Process in operations management', International Journal of Production Economics, Vol. 138, pp. 215-241.

Saaty, T. L. and Shih, H.S.(2009) 'Structures in decision making: On the subjective geometry of hierarchies and networks', European Journal of Operational Research, Vol. 199,pp. 867-872.

Shih, H.S., Shyur, H.J. and Lee,E.S. (2007) 'An extension of TOPSIS for group decision making', Mathematical and Computer Modelling, Vol. 45,pp.801-813. 
Srdjevic, B. (2005) 'Combining different prioritization methods in the analytic hierarchy process synthesis', Computers \& Operations Research, Vol. 32,pp.1897-1919.

Saghafian, S.and Hejazi, S.R. (2005) 'Multi-criteria Group Decision Making Using A Modified Fuzzy TOPSIS Procedure', Proceeding of 2005 the International Conference on Computational Intelligence for Modelling, Control and Automation, and International Conference on Intelligent Agents, Web Technologies and Internet Commerce (CIMCA-IAWTIC'05), ISSN 0-7695-2504-0/05.

Saaty, T. L.(2004) 'Decision Making - The Analytic Hierarchy and Network Process (AHP/ANP)', Journal of Systems Science and Systems Engineering, Vol.13,No.1,pp. 1-34.

Shih,H.-S.,Lin,W.-Y. and Lee,E. S. (2001) ‘ Group Decision Making for TOPSIS’, IEEE,ISSN:07803-7078-3/01.

Schoner, B., Choo,E.U. and Wedley, W.C.(1997) 'A comment on "Rank disagreement: a comparison of multicriteria methodologies', Journal of Multi-Criteria Decision Analysis, Vol. 6 pp.197-200.

Saaty, T.L. (1994) 'Highlights and critical points in the theory and application of the analytic hierarchy process', European Journal of Operational Research, Vol. 74,pp. 426-447.

Saaty, T. L. (1990) 'Eigenvector and logarithmic least squares', European Journal of Operational Research, Vol. 48, pp.156-160.

Schoner, B.,Wedley, W.C.(1989) 'Ambiguous criteria weights in AHP: consequences and solutions', Decision Sciences, Vol. 20, pp. 462-475.

Shim J.P. (1989) 'Bibliographical Research on the Analytic Hierarchy Process (AHP)', SocioEconomic Planning Science., Vol. 23, No. 3, pp. 161-167.

Saaty, T. L and Vargas, L. G (1984) 'The Legitimacy of Rank Reversal', OMEGA International Journal of Management Science, Vol. 12, No 5. pp. 513-516.

Taleizadeh, A. A., Niaki, S. T. A. and Aryanezhad, M.B.(2009) 'A hybrid method of Pareto, TOPSIS and genetic algorithm to optimize multi-product multi-constraint inventory control systems with random fuzzy replenishments', Mathematical and Computer Modelling, Vol. 49, pp.1044-1057.

Tsou, C.S. (2008) 'Multi-objective inventory planning using MOPSO and TOPSIS', Expert Systems with Applications, Vol. 35, pp. 136-142.

Vaidya, O. S. and Kumar, S.(2006) 'Analytic hierarchy process: An overview of applications', European Journal of Operational Research, Vol.169, pp.1-29.

Xia, W. and Wu, Z.(2007) 'Supplier selection with multiple criteria in volume discount environments',Omega,Vol.35,pp.494-504.

Wang, T. C. and Lee, H.D.(2009) 'Developing a fuzzy TOPSIS approach based on subjective weights and objective weights', Expert Systems with Applications, Vol. 36, pp. 8980-8985.

Wang, J.W., Cheng, C.H. and Cheng, H. K. (2008) 'Fuzzy hierarchical TOPSIS for supplier selection', Applied Soft Computing, doi:10.1016/j.asoc.2008.04.014. 


\section{Krishnendu Mukherjee}

Whitaker, R. (2007) 'Validation examples of the Analytic Hierarchy Process and Analytic Network Process', Mathematical and Computer Modelling, Vol. 46, pp.840-859.

Wang, Y.J. and Lee, H.S. (2007) 'Generalizing TOPSIS for fuzzy multiple-criteria group decisionmaking', Computers and Mathematics with Applications, Vol. 53, pp. 1762-1772.

Wang, Y.M. and Elhag, T. M. S. (2006) 'An approach to avoiding rank reversal in AHP', Decision Support Systems, Vol. 42, pp. 1474-1480.

Zanakis, S.H., Solomon, A., Wishart, N., Dublish, S., (1998) 'Multi-attribute decision making: a simulation comparison of selection methods', European Journal of Operational Research, Vol. 107, pp.507-529.

Zeleny, M. (1974) 'A Concept of Compromise Solutions and the Method of the Displaced Ideal', Computers and Operations Research, Vol.1, pp.479-496.

\section{List of tables and figures}

Table 1.1 Multi-criteria analysis (Source: Jacquest Teghem Jr et al., 1989)

\begin{tabular}{|l|l|l|l|}
\hline Method & Criteria & Information of the criteria & Characteristics of results \\
\hline Saaty & Ordinary & Hierarchical & Total pre-order \\
\hline ORESTE $^{*}$ & Ordinary & Total pre-order & Partial pre-order \\
\hline PROMETHEE I & Any & Preference function & Partial pre-order \\
\hline PROMETHEE II & Any & Preference function & Total pre-order \\
\hline PROMETHEE III & Any & Preference function & Partial or total \\
\hline ELECTRE I & Quasi & Weight & Set of good actions \\
\hline ELECTRE II & Quasi & Weight & Total pre-order \\
\hline ELECTRE III & Pseudo & Weight & Partial pre-order \\
\hline ELECTRE IV & Pseudo & None & Partial pre-order \\
\hline
\end{tabular}

*ORESTE (organisation, rangement et Synth\&e de donnCes relarionnelles), ELECTRE (

Elimination Et Choix Traduisant la Realité), PROMETHEE (Preference Ranking Organization

Method for Enrichment of Evaluations), TOPSIS (Technique for Order Preference by Similarity to

Ideal Solution), AHP (analytic hierarchy process)

Table 1.2 Random index

\begin{tabular}{|l|l|l|l|l|l|l|l|l|l|l|l|l|l|}
\hline $\begin{array}{l}\text { Matrix } \\
\text { order }\end{array}$ & 1,2 & 3 & 4 & 5 & 6 & 7 & 8 & 9 & 10 & 11 & 12 & 13 & 14 \\
\hline RI & 0 & 0.52 & 0.89 & 1.12 & 1.26 & 1.36 & 1.41 & 1.46 & 1.49 & 1.52 & 1.54 & 1.56 & 1.58 \\
\hline
\end{tabular}


Table 1.3 Different scales for comparing two alternatives (Source:

Ishizaka and Labib, 2011)

\begin{tabular}{|c|c|c|c|c|}
\hline Sl.No. & Scale type & Proposed by & Definition & Parameters \\
\hline 1 & Linear scale & Saaty, 1977 & $\mathrm{C}=\mathrm{a} . \mathrm{x}$ & $a>0 ; x=\{1,2, \ldots \ldots, 9\}$ \\
\hline 2 & Power scale & Harker \&Vargas, 1987 & $\mathrm{C}=\mathrm{x}^{\mathrm{a}}$ & $a>0 ; x=\{1,2, \ldots \ldots, 9\}$ \\
\hline 3 & Geometric & Lootsma, 1989 & $\mathrm{C}=\mathrm{a}^{\mathrm{x}-1}$ & $\begin{array}{lccc}a>0 ; & x= & \{1,2, \ldots \ldots ., 9\} & \text { or } \\
x=\{1,1.5, . ., 4\} & \text { or other step } & \\
\end{array}$ \\
\hline 4 & Logarithmic & $\begin{array}{l}\text { Ishizaka, Balkenborg, \& } \\
\text { Kaplan, } 2010\end{array}$ & $\mathrm{C}=\log _{a}(x+(a-1))$ & $a>0 ; x=\{1,2, \ldots \ldots, 9\}$ \\
\hline 5 & Root square & Harker \&Vargas, 1987 & $\mathrm{C}=\sqrt[a]{x}$ & $a>0 ; x=\{1,2, \ldots \ldots, 9\}$ \\
\hline 6 & Asymptotical & Dodd \& Donegan, 1995 & $\mathrm{C}=\tanh ^{-1}\left(\sqrt{3} \frac{(x-1)}{14}\right)$ & $\mathrm{x}=\{1,2, \ldots \ldots, 9\}$ \\
\hline 7 & Inverse linear & Ma \& Zheng,1991 & $C=\frac{9}{(10-x)}$ & $\mathrm{x}=\{1,2, \ldots \ldots, 9\}$ \\
\hline 8 & Balanced & Salo \& Hamalainen, 1997 & $\mathrm{C}=\frac{W}{(1-W)}$ & $\mathrm{w}=\{0.5,0.55,0.6, \ldots, 0.9\}$ \\
\hline
\end{tabular}

Table 1.4 Hybrid AHP

\begin{tabular}{|c|c|c|c|}
\hline $\begin{array}{l}\text { Sl. } \\
\text { No. }\end{array}$ & Author/s & $\begin{array}{c}\text { Journal/Conference } \\
\text { Name and Year }\end{array}$ & Remarks \\
\hline 1 & $\begin{array}{l}\text { Ali Najmi and Ahmad } \\
\text { Makui }\end{array}$ & $\begin{array}{l}\text { International Journal of } \\
\text { Industrial Engineering } \\
\text { Computations. } \\
2010\end{array}$ & $\begin{array}{l}\text { AHP and DEMATEL are integrated. AHP cannot solve } \\
\text { interrelations among different criteria. ANP could be used in } \\
\text { such situation. Another alternative solution is to integrate } \\
\text { AHP and DEMATEL. DEMATEL Method created by the } \\
\text { Battelle Geneva Association is based on the concept of pair- } \\
\text { wise comparison of decision characteristics such as solutions } \\
\text { alternative, criteria, and etc. }\end{array}$ \\
\hline 2 & $\begin{array}{l}\text { David P. Lilly, John Cory, } \\
\text { and Bill Hissem }\end{array}$ & $\begin{array}{l}2009 \text { Oxford Business } \\
\text { \& Economics } \\
\text { Conference Program. }\end{array}$ & $\begin{array}{l}\text { Basically Principal Component Analysis (PCA) takes a set of } \\
\text { data in matrix form, preconditions the data, extracts eigen } \\
\text { values and eigenvectors, rotates the data and condenses many } \\
\text { correlated variables into a lesser number of uncorrelated } \\
\text { principle components. A principle component is a linear- } \\
\text { weighted combination of optimally weighted observed } \\
\text { variables. There are several methods to conduct PCA } \\
\text { including the variance mode, and the correlation mode. } \\
\text { Worked on Lafarge Texada Plant,Vancouver,Canada. }\end{array}$ \\
\hline 3 & A. Azadeh, H.R. Izadbaksh & $\begin{array}{l}\text { International Journal of } \\
\text { Industrial Engineering. } \\
2008\end{array}$ & $\begin{array}{l}\text { An integrated approach of PCA and AHP is applied to } \\
\text { compare result with DEA and AHP. Their integrated } \\
\text { approach shows exact rankings whereas DEA and AHP } \\
\text { shows incomplete and non-exact ranking of plant layout. }\end{array}$ \\
\hline 4 & Zixue Guo, Yi Zhang & $\begin{array}{l}\text { IEEE conference. } \\
2010 .\end{array}$ & $\begin{array}{l}\text { AHP-PCA model involves two stages: Introduce index } \\
\text { weight and embody in weighted standardization matrix. }\end{array}$ \\
\hline 5 & Weijun Xia, Zhiming Wu & $\begin{array}{l}\text { Omega } \\
2007\end{array}$ & $\begin{array}{l}\text { In AHP, a decision maker is asked to estimate pair wise } \\
\text { comparison ratios with respect to strength of preference } \\
\text { between subjects of comparison. Thus AHP is deeply related } \\
\text { to human judgment. For reducing subjective extent of human } \\
\text { judgment, they proposed decision table approach for } \\
\text { obtaining more objective weights. Conditional entropy and } \\
\text { attribute significance concepts in rough sets theory are used } \\
\text { in AHP to improve the judgment consistency. }\end{array}$ \\
\hline 6 & Ehsan Akhlaghi & $\begin{array}{l}\text { World Academy of } \\
\text { Science, Engineering }\end{array}$ & Used fuzzy rough set theory (RST). \\
\hline
\end{tabular}


Krishnendu Mukherjee

\begin{tabular}{|l|l|l|l|}
\hline 7 & $\begin{array}{l}\text { Chen-Guang Guo, Yong- } \\
\text { Xian Liu, Shou-Ming Hou, } \\
\text { Wei Wang }\end{array}$ & $\begin{array}{l}\text { International Journal of } \\
\text { Automation and } \\
\text { Computing. November } \\
2010 .\end{array}$ & Fuzzy AHP and RST. \\
\hline 8 & $\begin{array}{l}\text { Te-Sheng Li, Hsing-Hsin } \\
\text { Huang }\end{array}$ & $\begin{array}{l}\text { Expert Systems with } \\
\text { Applications. } \\
2009\end{array}$ & $\begin{array}{l}\text { TRIZ, an acronym for the Theory of Inventive Problem } \\
\text { Solving, began in 1946 when Altshuller, a mechanical } \\
\text { engineer, began to study patents in the Russian Navy. They } \\
\text { proposed Fuzzy AHP and TRIZ for product design. }\end{array}$ \\
\hline
\end{tabular}

Table 1.5 Application of AHP

\begin{tabular}{|l|l|l|l|}
\hline \multicolumn{1}{|c|}{ Authors } & \multicolumn{1}{|c|}{ Period } & $\begin{array}{c}\text { No of papers } \\
\text { referred }\end{array}$ & \multicolumn{1}{c|}{ No of application areas identified } \\
\hline Jung. P. Shim & $1979-1988$ & 141 & 31 \\
\hline $\begin{array}{l}\text { Omkarprasad S. Vaidya } \\
\text { and Sushil Kumar }\end{array}$ & Prior to 1990 to 2003 & 154 & $\begin{array}{l}\text { Referred papers are categorized into 10 different } \\
\text { areas and each area is further subdivided into 9 sub- } \\
\text { areas. }\end{array}$ \\
\hline $\begin{array}{l}\text { Nachiappan Subramanian } \\
\text { and Ramakrishnan } \\
\text { Ramanathan }\end{array}$ & 1990 to 2009 & 291 & $\begin{array}{l}\text { Area related to operations management is } \\
\text { categorized into 5 areas and each area is further } \\
\text { divided into sub-categories. }\end{array}$ \\
\hline
\end{tabular}

Table 1.6 Comparison of characteristics between AHP and TOPSIS (source: Shih et al., 2007)

\begin{tabular}{|c|c|c|}
\hline Characteristics & AHP & TOPSIS \\
\hline 1.Category & $\begin{array}{l}\text { Cardinal information, information } \\
\text { on attribute, MADM }\end{array}$ & $\begin{array}{l}\text { Cardinal information, } \\
\text { information on attribute, } \\
\text { MADM }\end{array}$ \\
\hline 2.Core process & $\begin{array}{l}\text { Pairwise comparison (cardinal } \\
\text { ration measurement) }\end{array}$ & $\begin{array}{l}\text { The distance from PIS and } \\
\text { NIS (cardinal absolute } \\
\text { measurement) }\end{array}$ \\
\hline 3.Attribute & Given & Given \\
\hline 4.Weight elicitation & Pairwise comparison & Given \\
\hline 5. Consistency check & Provided & None \\
\hline $\begin{array}{lcc}6 . & \text { No of attributes } \\
\text { accommodated } & \end{array}$ & $\begin{array}{lr}7 \pm 2 & \text { or } \\
\text { decomposition }\end{array}$ & Many more \\
\hline $\begin{array}{l}\text { 7. No of alternatives } \\
\text { accommodated }\end{array}$ & $7 \pm 2$ & Many more \\
\hline 8. Others & Compensatory operation & Compensatory operation \\
\hline
\end{tabular}

Table 1.7 Some normalization methods for TOPSIS (source: Shih et al., 2007)

\begin{tabular}{|c|c|}
\hline 1 & Vector normalization: \\
& $r_{i j}=\frac{x_{i j}}{\sqrt{x_{i j}^{2}}}, \quad$ where $i=1,2,3 \ldots \ldots$, m and $j=1,2,3 \ldots, n$ \\
\hline 2 & Linear normalization: \\
& $r_{i j}=\frac{x_{i j}}{x_{i j}^{*}}$, where $i=1,2, \ldots$, m and $j=1,2, \ldots \ldots, n ;$ \\
\hline
\end{tabular}


Past, present and future of AHP and TOPSIS

\begin{tabular}{|c|c|}
\hline & $\begin{array}{c}x_{j}^{*}=\max _{\mathrm{i}}\left\{x_{i j}\right\} \text { for benefit attributes } \\
r_{i j}=\frac{x_{j}^{\tilde{j}}}{x_{i j}}, \text { where } i=1,2, \ldots, m \text { and } j=1,2, \ldots, n ; x_{j}^{\tilde{N}}=\min _{i}\left\{x_{i j}\right\} \\
\text { Or } r_{i j}=1-\frac{x_{i j}}{x_{i j}^{*}} \text {,where } i=1,2, \ldots, n \text { and } j=1,2, \ldots, m ; x_{j}^{*}=\max _{j}\left\{x_{i j}\right\} \text { for cost attributes }\end{array}$ \\
\hline 3 & $\begin{array}{l}\text { Linear normalization: } \\
\qquad \begin{aligned} r_{i j} & =\frac{x_{i j}-x_{i j}^{\tilde{i j}}}{x_{i j}^{*}-x_{i j}^{\tilde{j}}} \text { for benefit attributes } \\
r_{i j} & =\frac{x_{i j}^{*}-x_{i j}}{x_{i j}^{*}-x_{i j}^{\tilde{j}}} \text { for cost attributes }\end{aligned}\end{array}$ \\
\hline 4 & $\begin{array}{l}\text { Linear normalization: } \\
\qquad r_{i j}=\frac{x_{i j}}{\sum_{i=1}^{m} x_{i j}} \text {, where } i=1,2, \ldots, m \text { and } j=1,2, \ldots \ldots, n\end{array}$ \\
\hline 5 & $\begin{array}{l}\text { Non-monotonic normalization: } \\
\qquad e^{-\frac{z^{2}}{2}}, z=\frac{x_{i j}-x_{j}^{0}}{\sigma_{j}} ; x_{j}^{0} \text { is the most favorable value } \\
\sigma_{j} \text { is standard deviation of alternative ratings with respect to } j^{\text {th }} \text { attribute }\end{array}$ \\
\hline
\end{tabular}

Table1.8 Distance measures (functions) for TOPSIS (source: Shih et al., 2007)

\begin{tabular}{|c|c|}
\hline 1 & $\begin{array}{l}\text { Minkowski's Lp metrics: } \\
\qquad L_{p}(x, y)=\left\{\sum_{j=1}^{n}\left|x_{j}-y_{j}\right|^{p}\right\}^{\frac{1}{p}} \text {, where } p \geq 1 \text { and with } n \text { dimensions } \\
\text { (i) Manhattan (city block) distance } \mathrm{p}=1 \\
\text { (ii) Euclidean distance } \mathrm{p}=2 \\
\text { (iii) Tchebycheff distance } \mathrm{p}=\infty\end{array}$ \\
\hline 2 & $\begin{array}{l}\text { Weighted Lp metrics: } \\
\qquad L_{p}(x, y)=\left\{\left(w_{j} \sum_{j=1}^{n}\left|x_{j}-y_{j}\right|\right)^{p}\right\}^{\frac{1}{p}} \text {, where } p \in\{1,2, \ldots\} \cup\{\infty\} \\
\mathrm{w}_{\mathrm{j}} \text { is the weight on the } \mathrm{j}^{\text {th }} \text { dimension }\end{array}$ \\
\hline
\end{tabular}


Krishnendu Mukherjee

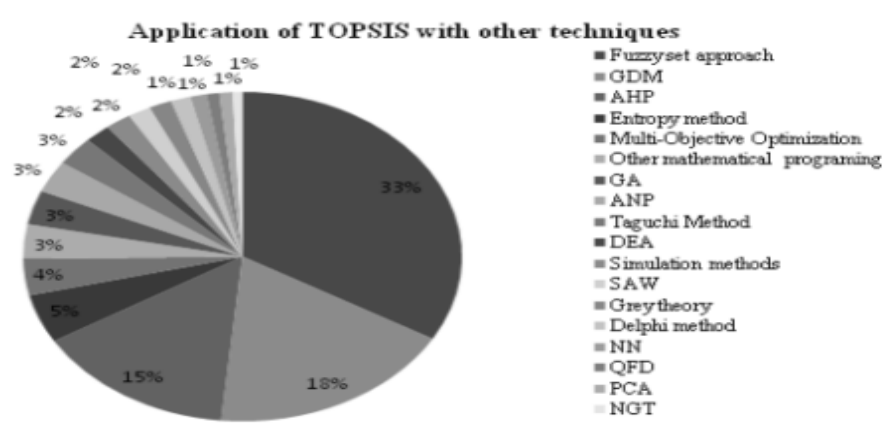

Fig1. Distribution of research papers on combined TOPSIS since 2000 onward. 